Research, part of a Special Feature on Applying Landscape Science to Natural Resource Management

\title{
Understanding Public Support for Indigenous Natural Resource Management in Northern Australia
}

\author{
$\underline{\text { Kerstin K. Zander }}^{1,2}$
}

\begin{abstract}
Increased interest in indigenous-led natural resource management (NRM) on traditionally owned land in northern Australia has raised important questions in relation to policies that compensate indigenous Australians for providing environmental services. A choice experiment survey was mailed out to respondents across the whole of Australia to assess if and to what extent Australian people think that society benefits from these services and how much they would pay for them. More than half the respondents would in principle support indigenous NRM in northern Australia, with a high willingness to pay for carbon, biodiversity, and recreational services. Social aspects of indigenous NRM, however, were not valued by the society, emphasizing the need for awareness raising and clarifications of benefits that indigenous people gain while carrying out land management on their traditional country. Any marketing campaign should take into account preference variation across Australian society, which this research shows is substantial, particularly between people from the north and those from the south. People from the south were more likely to support indigenous NRM, a significant finding for campaigns targeting potential donors.
\end{abstract}

Key Words: choice experiment; conservation marketing; environmental services; PES; traditional country; willingness to pay

\section{INTRODUCTION}

Indigenous-held land makes up $20 \%$ of the Australian continent or about 1.5 million square kilometers, mainly covering intact desert and tropical savannah (Altman et al. 2007). The land is only marginally productive (Altman et al. 2007) and the opportunity costs of alternative land management, for example, agriculture, are very low. If this land can be managed and even used to generate some money, e.g., carbon offsetting for companies, Reducing Emissions from Deforestation and Forest Degradation (REDD), international emissions trading schemes, the whole of Australian society could benefit and the investment spent on people providing environmental services could be profitable in the future (Altman 2007). Nonindigenous natural resource management (NRM) on this land is unlikely because the land is owned by indigenous people, and permission is needed to access it. However, indigenous ranger groups exist and even though the work is usually poorly paid and often linked to welfare payments, the demand for these jobs is higher than the number of ranger positions available. There is currently little money available for provision of incentives and/or conservation partnerships on indigenous and/or pastoral lands and the management budget of most existing national parks services is inadequate (Garnett et al. 2008). Many indigenous Australians are already engaged in NRM without any payments at all. In both cases they are "poorly remunerated for the provision of a range of environmental services" (Altman 2007:7) while some parts of the broader Australian society free-ride on this provision (Muller 2008).

The concept of Payments for Environmental Services (PES) has become very popular over the last 20 years, advocating a solution for cost-effective NRM (Ferraro and Simpson 2002,
Engel et al. 2008) with mixed effects on poverty alleviation (Muradian et al. 2010). The concept has been particularly successful in the neotropics (Rapidel et al. 2011) and PES-like schemes have also been established in southern Australia (Connor et al. 2008). It has been suggested that PES could be the new paradigm for NRM on indigenous-held land in northern Australia (Altman 2007, Garnett et al. 2008, Pearson and Gorman 2010). For any PES-like schemes to work, the providers' perspectives have to be understood as well as those of the beneficiaries, including how much the beneficiaries would be willing to pay for which services and what they expect in return. Both aspects are under-researched in the context of indigenous Australia.

In the case of indigenous NRM, there is increasing evidence that the providers also benefit from engagement in NRM beyond the financial reward they might receive for delivering the services. Medical research (Scrimgeour 2007, Campbell 2011) has corroborated the view of indigenous people (Burgess et al. 2005, Johnston et al. 2007) that spending time on country improves physical health. This can be attributed not only to the physical activity and diet of people living in very remote areas (McDermott et al. 1998) but also the psychological importance of spending time on the traditional country to which they have a spiritual connection (Garnett and Sithole 2007, Green 2008). This results in substantial savings in health expenditure (Campbell et al. 2011), which can benefit all Australian taxpayers. There is thus an indirect benefit to providers beyond the improved land management, though this may not be well known or affect willingness to pay for indigenous land management.

Assessing potential beneficiaries' views of benefits of NRM can help to establish market-based incentive schemes, such as 
Table 1. Attributes and their levels used to describe the hypothetical scenarios in the choice experiment.

\begin{tabular}{|c|c|c|c|}
\hline Attribute & $\begin{array}{l}\text { Possible levels for "indigenous land } \\
\text { management" scenarios }\end{array}$ & $\begin{array}{l}\text { Possible levels for "maintaining current } \\
\text { management" scenario (SQ) }\end{array}$ & $\begin{array}{l}\text { Service/ } \\
\text { Benefit }\end{array}$ \\
\hline $\begin{array}{l}\text { (1) Health of native animal and plant } \\
\text { communities }\end{array}$ & $\begin{array}{l}\text { - Improving } \\
\text { - Stable }\end{array}$ & $\begin{array}{l}\text { - Stable } \\
\text { - Deteriorating }\end{array}$ & Biodiversity \\
\hline (2) Attractiveness for recreational use & $\begin{array}{l}\text { - Good } \\
\text { • Fair }\end{array}$ & $\begin{array}{l}\text { - Poor } \\
\text { - Fair }\end{array}$ & $\begin{array}{l}\text { Scenery/ } \\
\text { Recreational }\end{array}$ \\
\hline (3) Benefits for indigenous people & $\begin{array}{l}\text { - Better health } \\
\text { - Better transfer of indigenous knowledge } \\
\text { - Less dependency on the government }\end{array}$ & - No additional benefits & $\begin{array}{l}\text { Social/ } \\
\text { Cultural }\end{array}$ \\
\hline (4) Greenhouse gas emissions & $\begin{array}{l}\text { - Reducing } \\
\text { - Stable }\end{array}$ & $\begin{array}{l}\text { - Increasing } \\
\text { - Stable }\end{array}$ & Carbon \\
\hline $\begin{array}{l}\text { (5) Annual contribution into a conservation } \\
\text { fund (AUS\$) }\end{array}$ & $25,50,100,200,300$ & 0 & \\
\hline
\end{tabular}

PES, for indigenous Australians. Investment in potential indigenous NRM is competing with other government priorities and additional funding is needed from alternative sources, for example NGOs, industry, e.g., offsetting carbon as already done in western Arnhem Land ${ }^{[1]}$, or voluntary payments. To secure additional funding, it is important to understand the value of environmental services that indigenous people can supply on their traditional country to the broader Australian society. Understanding and publicizing these values can help raise awareness of the public good, value of particular environmental services, and lead to the provision of additional money via voluntary payments (Farley and Costanza 2010). To assess what the Australian public as potential beneficiaries think about indigenous NRM, a nationwide postal survey, which included a choice experiment, was conducted. More specifically, the goal was to understand which services Australians thought had the highest benefits, and if there were different views across Australian society.

\section{METHODS}

\section{How to measure the value of different services}

Many environmental services, such as biodiversity and cultural values, have indirect benefits that cannot be assessed on the market. Valuing all direct and indirect use values as well as intangible nonuse values that arise from the provision of environmental services requires the application of nonmarket valuation techniques. I applied a choice experiment, a widely used and accepted method to evaluate environmental and public goods (Hanley et al. 1998). A choice experiment is survey based and obtains information from respondents by eliciting their preferences for a set of hypothetical scenarios (Adamowicz et al. 1998). The scenarios in this study described indigenous NRM that yielded certain environmental and social benefits. Each management scenario came with a cost that would hypothetically be borne by respondents. The environmental benefits from these scenarios accrue to the whole Australian society, the social benefits accrue to the indigenous providers, and, indirectly, also to the whole society.

Respondents were presented with so-called choice sets, including three different scenarios (Appendix 1) from which they chose the one they preferred most. Two of these scenarios described NRM scenarios in which additional money was available to employ indigenous people, and the third scenario was always a status quo (SQ) scenario, in which no additional money would be available, so no social benefits would result and environmental conditions would at best stay stable or deteriorate. Attributes and levels for the design were initially derived from in-depth interviews with experts in Darwin (from Charles Darwin University, the North Australia Indigenous Land and Sea Management Alliance, and indigenous rangers), and a literature review on the use of choice experiments to valuate environmental services in other countries. The attributes and levels were then tested in a pilot study with random respondents in Darwin. On the basis of the discussions, I decided to include three environmental benefits: increase in biodiversity, improvement of recreational condition, and decline in greenhouse gas (GHG) emissions, with different levels for each (Table 1). For example, for the attribute representing the biodiversity service, the levels might be 'improving' and 'stable' (health of native animals and plants) for the management scenarios and 'stable' and 'deteriorating' for the SQ scenario. The choice of attributes is consistent with a classification of environmental services as regulating (climate stability), cultural (including recreation/scenery), provisioning, supporting, and biodiversity (MEA 2003, Daily et al. 2009). As social benefits, I included 'better health' from 
spending time on their traditional country while providing environmental services (Garnett et al. 2009), greater transfer of indigenous knowledge when spending time on the traditional country with younger generations, and less dependency on the government resulting from market-based nonsubsidized income generation (Altman and Jordan 2009). The payment vehicle was framed as an annual voluntary contribution/donation to a fund dedicated to indigenous NRM. This cost attribute had six levels: A $\$ 0$ for the SQ and levels between $\mathrm{A} \$ 25$ and $\mathrm{A} \$ 300$ for the management scenarios.

I applied a Bayesian approach to combine the attributes describing the scenarios and their levels into choice sets. Using the software Ngene (Institute of Transport and Logistics Studies 2007), a design under $\mathrm{D}_{\mathrm{P}}$-efficiency criterion with 30 choice sets was created. I derived prior parameter information from a pilot phase with 30 respondents, which I used to create the final design. I compared different designs based on a $\mathrm{D}_{\mathrm{P}^{-}}$ error measure of design efficiency of the same dimension and chose the one with the lowest error (Rose et al. 2008). From the 30 final sets, I kept 21 and removed 9 that were unrealistic and/or required no trade-offs. The remaining 21 choice sets were randomly blocked into 3 versions and 7 sets were included in a questionnaire. Each version was used the same number of times. In addition, I accounted for a potential leftright bias by alternating the order of appearance of the two indigenous land management scenarios in the choice sets.

To analyze the choice data, I estimated random parameter logit (RPL) models because of their flexible assumptions, because they can address unobserved preference heterogeneity (Train 1998, Hensher et al. 2005), and because they can take full advantage of panel data (one respondent attending to a series of choice sets; Hensher et al. 2005). Specifics of RPL models are covered by Hensher and Greene (2003) or Train (2003). Individual-specific willingness-to-pay estimates for the attributes were derived from the RPL by simulation from the chosen distribution (Hensher et al. 2005). To ensure positive parameters estimated for the cost attribute, its distribution was specified as constraint triangular (Hensher and Greene 2003). All other random parameters were assumed to be normally distributed because respondents might like or dislike an attribute. The model was based on 120 Haltom draws. The willingness-to-pay estimates were calculated as the negative ratio of the coefficients of the attribute of interest, divided by the coefficient of the cost attribute. The willingness-to-pay estimates express the degree of utility a respondent has for an attribute. Using the parametric bootstrapping technique (Krinsky and Robb 1986), I estimated a distribution of 10,000 observations for each willingness-to-pay estimate by drawing from a multivariate normal distribution parameterized with the coefficient and standard deviation obtained from the models. This method also provides the $95 \%$ confidence intervals for each willingness-to-pay estimate. Following Hanemann (1984), the willingness-to-pay estimates for single attributes were added up, indicating the consumer surplus of investing in indigenous NRM that results in improved health of native plants and animals, attractiveness for recreational use, and declining GHG emissions.

Other responses not related to the choices were analyzed descriptively using frequency tables. Chi-square analyses were used to compare results of interest between groups, for example, between people from the south and from the north.

\section{Questionnaire}

I used a semistructured questionnaire that consisted of three parts: (1) questions related to respondents' socioeconomic status, (2) the choice experiment including prior information on activities that indigenous people commonly carry out on their land and their potential benefits, and (3) follow-up questions from the choice experiment. A Likert-scale question was included in the first part of the questionnaire asking respondents to rate their interest in aboriginal traditions and culture from 'not at all interested' (1), to 'a little bit interested' (2), to 'very interested'(3), to 'fascinated by it' (4). The question was included to reveal respondents' general attitude toward indigenous Australians issues and it can also be used as proxy for knowledge about aboriginal culture. A personalized endorsement and cover letter in plain English language explaining the purpose of the survey, how to complete it, and stating that the survey was voluntary and anonymous accompanied each questionnaire.

\section{Sampling and survey procedure}

We sent out 4600 questionnaires to urban addresses across Australia. Some envelopes were expected to be undeliverable and from those that could be delivered, I aimed to receive 1000 completed questionnaires back, which would mean a response rate of about 20\%. Southern Australia is much more populated than the northern Australia and hence about two-thirds of the questionnaires (3000) were distributed there. Five hundred questionnaires were mailed to addresses in the most populated states Victoria, New South Wales, and Queensland, 400 each to West Australia and South Australia, 300 to Tasmania, 250 to the Australian Capital Territory, and 150 to the Northern Territory (Alice Springs). One thousand six hundred questionnaires were mailed to addresses across northern Australia, which is where most indigenous people live and where most ranger employment occurs. In the Northern Territory, this included urban areas north of Alice Springs (Tennant Creek, Timber Creek, Katherine, and Darwin). In Queensland, I defined the north as urban areas with postal service above the Tropic of Capricorn. The north of Western Australia mainly included the regional towns of Broome, Derby, and Kununnurra. All addresses were randomly selected from the most recent telephone directory ('White Pages'). Although there will have been some bias arising from this, it was felt that people who had themselves listed in a telephone directory were more likely to remain at an address than 
commercially available address lists. Generalizations from the sample should be made cautiously because agreement to respond means that the sample is self-selected, possibly leading to a sample of people with stronger opinions than the population average. To maximize coverage of potential respondents I had to make a trade-off between the number of surveys sent out and the effort made to retrieve completed surveys. Thus, the investment in measures to increase the response rate, such as including a token, using color photographs and colored questionnaires, sending out postcards prior to the survey, and conducting phone and mail follow-up reminders (Dillman et al. 2009), was instead put into maximizing the number of surveys sent out in an effort to obtain as many truly voluntary returns as possible.

\section{RESULTS}

\section{Response rate and sample size}

The overall response rate of those questionnaires delivered was 9.6\% (9.5\% from southern Australia and 9.8\% from northern Australia). The final dataset included 393 respondents (136 from the north and 257 from the south) with some entries having to be removed before analysis because respondents did not complete at least one of the choice experiment questions (in $85 \%$ of the cases) or because they said they did not understand the choice experiment (in 15\% of the cases). In northern Australia 13\% of questionnaires came back undeliverable, probably because of the high population turnover rate (Carson 2011), with only 10\% being returned in southern Australia. Another 69 respondents (4\%) in northern Australia and $20(<1 \%)$ in southern Australia sent back unfilled questionnaires. Although the overall return rate was lower than aimed for, low response rates have also been reported in other recent Australia postal surveys in environmental studies (Adams et al. 2012) and health studies (Crouch et al. 2011). Also, although any survey based on selfselected participants will be biased, I have no reason to believe that my sample was any more biased than if I had used persuasive techniques to increase the response rate. The wide range of opinions expressed in the returns also suggests that the results probably do reflect general opinion, and that regional comparisons in particular are unlikely to have changed with a more comprehensive sampling technique.

\section{Sample characteristics}

Despite the low response rate, the sample reflects well the national averages in some key characteristics (ABS 2006). The sample had slightly more female than male respondents (51.8\% compared to $48.2 \%$ ), in line with the 2006 Census that showed the Australian population at $50.6 \%$ females and $49.4 \%$ males. Only $2.2 \%$ of the sample (nine respondents) identified themselves as aboriginal people or Torres Strait Islanders, which is comparable to the $2.3 \%$ indigenous Australians out of the total Australian population. Respondents' annual gross income was equally distributed among given categories with
$28.6 \%$ of respondents having an annual gross income of up to $\mathrm{A} \$ 39,999,25.5 \%$ had one of $\mathrm{A} \$ 40,000-69,999,20.4 \%$ of $\mathrm{A} \$ 70,000-99,999$, and $17.6 \%$ had one of $\mathrm{A} \$ 100,000$ or more. This compares well with a national annual median gross income of $A \$ 66,820$ (in 2006). The only major difference was that the median age of the sample (52 years; SD: 14 years) was higher than the national median of 37 years (ABS 2006).

Eleven percent of respondents were very fascinated by aboriginal traditions and culture, $34 \%$ were very interested, the majority, $46 \%$, a little bit interested, and $9 \%$ were not interested at all. Grouping 'fascinated by it' and 'very interested' together meant that fewer than half were interested (45\%; in the data analysis referred to as 'culturally interested') and the remaining $55 \%$ were uninterested in aboriginal culture.

\section{Who would and would not pay for indigenous natural resource management and why?}

Fifty-eight percent of respondents would pay for indigenous NRM and $42 \%$ would not (Table 2). Respondents from northern Australia were less likely to support indigenous NRM ( $\mathrm{P}=0.0024): 64 \%$ of respondents from the south compared to $48 \%$ from the north. Age (mean sample: 52, SD: 15) also had a significant impact on the general willingness to pay for indigenous NRM: the mean age of those willing to pay was 50 , the mean age of nonpayers was $55(\mathrm{P}=0.0049)$. Women were more likely to pay than men $(66 \%$ compared to $50 \%$; $\mathrm{P}$ $=0.0013)$. The level of education and income had no significant impact on the general willingness to support indigenous NRM. Respondents who were interested in aboriginal culture were significantly more likely to support indigenous NRM $(\mathrm{P}<0.0000)$. Seventy-one percent of those interested in aboriginal culture would pay, of those uninterested only $47 \%$ would pay (Table 2 ).

Table 2. Factors significantly determining respondents' general willingness to support an indigenous Payments for Environmental Services program.

\begin{tabular}{lccc}
\hline \hline & Would not pay & Would pay & $\mathrm{N}$ \\
\hline $\begin{array}{l}\text { Overall } \\
\text { Residency }\end{array}$ & $42 \%$ & $58 \%$ & 393 \\
$\begin{array}{l}\text { North Australia } \\
\text { South Australia }\end{array}$ & $52 \%$ & $48 \%$ & $136(35 \%)$ \\
Gender & $36 \%$ & $64 \%$ & $257(65 \%)$ \\
$\begin{array}{l}\text { Female } \\
\text { Male }\end{array}$ & $34 \%$ & $66 \%$ & $205(52 \%)$ \\
$\begin{array}{l}\text { Interest in aboriginal } \\
\text { culture }\end{array}$ & $50 \%$ & $50 \%$ & $188(48 \%)$ \\
Interested & & & \\
Uninterested & $29 \%$ & $71 \%$ & $177(45 \%)$ \\
& $53 \%$ & $47 \%$ & $215(55 \%)$ \\
\hline
\end{tabular}

The majority of nonpayers (52\%) listed lack of belief in indigenous NRM as one of the reasons they refused to pay, followed by the belief that it is the government's duty to pay indigenous people to look after their traditional country (24\%; 
Table 3). Some respondents said that they never donate on principle or already donate to other environmental causes, and a few (4\%) said they had no money to spare, with many of these stating that they would otherwise have paid. There was a statistically significant relationship $(\mathrm{P}<0.0000)$ between respondent's cultural interest and the reason they would not pay. From those people interested in aboriginal culture, only $10 \%$ would not pay because they do not believe that paying indigenous people for NRM would work, whereas only $10 \%$ of culturally interested respondents named this as the reason for not paying. The other reasons for not paying were not statistically different across respondents who were interested and uninterested in aboriginal culture.

Table 3. Respondents' reasons for not paying, and for paying for an indigenous Payments for Environmental Services program $(\%)$.

\begin{tabular}{lccc}
\hline \hline & $\begin{array}{c}\% \text { of } \\
\text { sample }\end{array}$ & $\mathrm{N}$ & $\begin{array}{c}\text { Protest } \\
\text { response }^{\dagger}\end{array}$ \\
\hline Reasons for not paying & & & \\
$\begin{array}{l}\text { Did not think that indigenous PES programs } \\
\text { will work }\end{array}$ & $52 \%$ & 86 & No \\
Believed that it is the government's duty & $24 \%$ & 40 & Yes \\
Never donate on principle & $13 \%$ & 21 & Yes \\
Already donate to other environmental causes & $6 \%$ & 10 & No \\
Lack of money & $4 \%$ & 6 & Yes \\
Reasons for paying & & & \\
Maintain a healthy environment & $97 \%$ & 201 & \\
Maintain aboriginal culture & $75 \%$ & 157 & \\
Contribution to job creation for aboriginal & $65 \%$ & 135 & \\
people & & & \\
\hline
\end{tabular}

A protest response is one in which respondents choose the status quo scenario in all presented choice sets, not because they have zero willingness-to-pay for the environmental services provided by indigenous people but because of other reasons (see e.g., Meyerhoff and Liebe 2009 for more details on how to handle protest responses).

Most of the respondents who were willing to pay would do so because they thought it would maintain a healthy environment (97\%, Table 3). Many (75\%) paid because they thought it would help to maintain aboriginal culture and $65 \%$ because they thought that indigenous NRM can create jobs for indigenous people. Multiple answers were allowed, and $46 \%$ of respondents named all three reasons offered whereas $27 \%$ named environmental and cultural reasons together. A few respondents $(8 \%)$ named only environmental reasons but no respondents named only cultural and job reasons on their own. This means that almost all respondents expect some kind of environmental improvement from environmental services provided by indigenous people in return for their voluntary contribution.

\section{The value of services}

Fifty-six of the nonpayers were identified as 'protesters'. This included those respondents who believed that the government should pay for indigenous NRM (40), those who never donate in principle (10), and those who lacked the money to make the hypothetical payment (6; Table 3 ). Protest behavior constitutes a problem in environmental valuation because these people do not have genuine zero value for indigenous NRM (Hanley et al. 2006), but rather chose not to pay because of other reasons, such as protesting against the concept that they have to trade off various attributes (Meyerhoff and Liebe 2009), protesting against any form of government action (von Haefen et al. 2005), or they 'disapprove of the principle of paying for environmental protection since they believe it should be required by law' (Hanley et al. 2006). Respondents who thought that the government was responsible for paying for indigenous NRM could indeed value highly the environmental services that result from it, but would rather have somebody else pay for it. They might even think that they indirectly pay for it through taxes. Including these protest responses would bias the results (Bateman et al. 2002) and these 56 respondents were thus excluded from the analysis. The subsequent model was therefore estimated with 337 respondents.

I ran a series of RPL models, omitting and including different attributes and introducing a variety of socioeconomic variables into the model as interactions with the attributes. The final model was selected based on likelihood ratio tests. The final model had a good model fit with a McFadden R 22 of 0.47 (McFadden 1974) and did not include the medium levels of the three variables describing environmental services, i.e., 'stable GHG emissions,' 'stable health of native plants and animals,' 'fair recreational attractiveness.' These were dropped from the model because they were insignificant (Table 3) and the likelihood ratio test suggested that the model fit was better without them. This means that respondents did not value a fair level of attractiveness any differently to poor recreational attractiveness, stable health of native plants and animals differently to declining health of native plants and animals, and stable GHG emissions any differently from increasing GHG emissions. From the three social benefits, only 'less dependency on the government' was significant. Respondents disliked 'less dependency on the government' compared with 'better transfer of indigenous knowledge' and 'better health' for which they had the same utility as having no additional benefit.

The coefficients for improving health of native plants and animals, a high level of attractiveness for recreation, and declining GHG emissions were positive and significant at the $1 \%$ level, indicating respondents' strong preferences for and utility of these attributes. The coefficient for the cost attribute was, as expected, negative, indicating that respondents would choose the cheaper scenario, all else being equal. The coefficient for the SQ constant was significant and negative, suggesting that the utility for the indigenous NRM scenarios was higher than for the 'no management' scenario. Out of the six attributes estimated in the final model, five had significant 
Table 4. Results of a choice experiment to determine willingness-to-pay for delivery of environmental services by indigenous people in northern Australia.

\begin{tabular}{|c|c|c|}
\hline Variable & Coefficient & SD \\
\hline Improved health of native animals and plants & $0.95 * * *$ & $0.82 * * *$ \\
\hline Good attractiveness for recreation & $0.80 * * *$ & $0.61 * * *$ \\
\hline Less dependency on government for indigenous people & $-0.58 * * *$ & \\
\hline Declining $\mathrm{GHG}^{\dagger}$ emissions & $1.25 * * *$ & $1.01 * * *$ \\
\hline Constant for $\mathrm{SQ}^{\ddagger}$ & $-4.29 * * *$ & $2.52 * * *$ \\
\hline Annual contribution to PES program & $-0.01 * * *$ & $0.01 * * *$ \\
\hline Good attractiveness for recreation $x$ Culturally interested ${ }^{\S}$ & $0.31^{*}$ & \\
\hline Declining GHG2 emissions x Culturally interested & $0.57 * * *$ & \\
\hline Improved health of native animals and plants x North Australia & $-0.53 * *$ & \\
\hline Declining GHG2 emissions x North Australia & $-0.39 *$ & \\
\hline \multicolumn{3}{|l|}{ Model fit: } \\
\hline Log-likelihood & & -1334.70 \\
\hline Pseudo R-squared & & 0.47 \\
\hline Number of observations & & 2307 \\
\hline Number of respondents & & 337 \\
\hline Halton draws & & 120 \\
\hline
\end{tabular}

***,**,*: Significance at $1 \%, 5 \%, 10 \%$ level

GHG: Greenhouse Gas

SQ: Status quo

${ }^{\S}$ The variable "Culturally Interested" was dummy coded, 1 for those respondents who were interested in aboriginal traditions and cultures, 0 for those uninterested (see Results).

I The variable "North Australia" was dummy coded, 1 for those respondents who lived in north Australia, 0 for those who lived in southern Australia.

standard deviations (Table 4), indicating that there is a high degree of unexplained heterogeneity within the sample.

The two socioeconomic variables 'North Australia' and 'culturally interested' had a significant impact on respondents' preferences for some attributes. Interaction effects showed that respondents from the north were significantly less likely to choose a scenario with 'improved health of native animals and plants' and 'declining GHG emissions' than respondents from the south, whereas respondents who were interested in aboriginal culture were more likely to choose a scenario with 'a high level of attractiveness for recreation' and 'declining GHG emissions' than respondents who were not uninterested.

Respondents showed the highest utility for carbon services that potentially arise from indigenous NRM (on average A \$128; Table 5). Leaving the social aspects aside, the total ecological value from indigenous NRM amounted to about A $\$ 300$ (bottom row in Table 5). Respondents from the north would pay less than the average for potential biodiversity ('health of native plants and animals') and carbon services, in total A $\$ 86$ less for indigenous NRM. Respondents who were interested in aboriginal culture had a higher utility from carbon and recreational services and would pay $\mathrm{A} \$ 82$ more for indigenous NRM than the average.

\section{What would indigenous natural resource management within a PES scheme look like?}

Forty-one percent of respondents thought that controlling feral and dangerous animals was the most important activity that indigenous people should carry out on their traditional country, followed by noxious weed control $(21 \%)$, coastal surveillance (14\%), and fire management (11\%; Figure 1). Some respondents $(8 \%)$ could not pick one activity but stated that all of them were equally important and interlinked. There was no significant impact of respondents' willingness to contribute to indigenous NRM, respondent's location, or their gender on the choice of the most important activity.

Fig. 1. Natural resource management activities respondents would prefer to see indigenous people performing (\%).

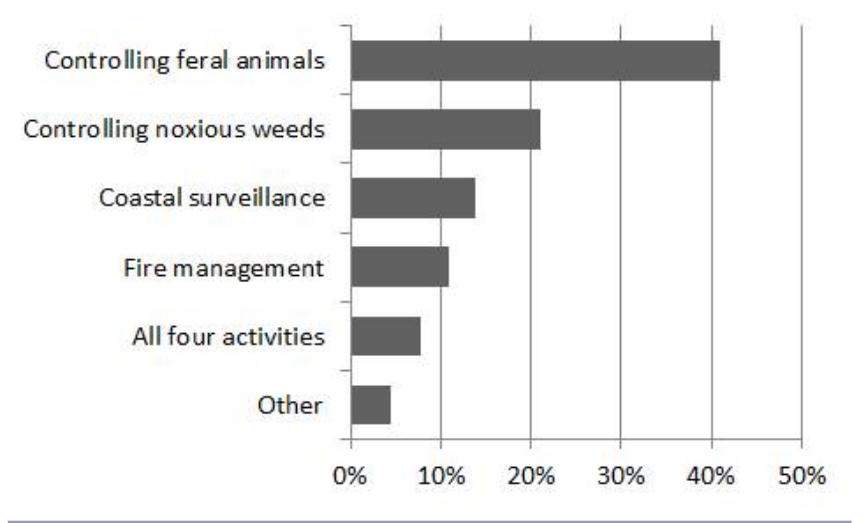

Most (60\%) of the respondents who would pay did not specify a finite length for their contributions and stated that they 
Table 5. Willingness-to-pay (in AUS\$) for different services and in total for an indigenous Payments for Environmental Services program in northern Australia, mean and [95\% confidence interval].

\begin{tabular}{|c|c|c|c|}
\hline & On average & People from the north & Culturally interested people \\
\hline Biodiversity service & $96[46-145]$ & $43[-7-92]$ & $96[46-145]$ \\
\hline Recreational service & $81[36-125]$ & $81[36-125]$ & $112[62-160]$ \\
\hline Carbon service & $127[61-189]$ & $88[22-150]$ & $184[118-246]$ \\
\hline Total & $301[248-353]$ & $209[155-261]$ & $389[335-441]$ \\
\hline
\end{tabular}

$1 \mathrm{US} \$=0.96$ AUS $\$$ (January 2012)

wanted to pay for as long as they were able. Some wished to pay for between 2 and 5 years (23\%), some for 10 and 15 years $(7 \%)$, or for more than 15 years $(5 \%)$.

\section{DISCUSSION}

Raising voluntary payments to finance indigenous NRM Given the limited opportunity for indigenous people to overcome economic disadvantage (Campbell 2011), indigenous NRM and PES programs could help to overcome the high levels of poverty that are pervasive in many aboriginal communities (Hunter 2006). The question is how can this money be collected and then made available to indigenous people. One way to collect voluntary donations could be through an intermediate agent, either an NGO or a comanaged government agency, such as the Indigenous Land Corporation, ILC. Acting as in situ environmental service buyers (Zabel and Engel 2010), the agent could combine external voluntary payments/donations with income from carbon trading schemes, creating a diverse portfolio of payments to secure continuous funding for indigenous NRM that could become independent of government funding. Many respondents were vague about how long they would be likely to contribute, many suggesting they would pay into a program for between two and five years, allowing some time to build up the portfolio of PES investors.

Who among those wishing to promote the values of indigenous NRM should be targeted for donations? I valued environmental services from the perspective of the wider Australian society, bearing in mind that environmental services are public goods, and one of the PES principles is that those who value and use the resources should pay for them (Balmford and Whitten 2003, TEEB 2010). Most Australians are in favor of indigenous NRM, although with large variations across the society, therefore it could be worthwhile for those wishing to promote the value of indigenous NRM to target those who favor the concept through appropriate marketing. Marketing of conservation to gain external financial support is most effective when focused on branded concepts, for example, flagship species or 'biodiversity hotspots' (Smith et al. 2010). Tropical northern Australia has two major marketable assets with respect to indigenous NRM and PES. First, northern Australia supports more than $25 \%$ of the tropical savannas remaining in the world and by far the most extensive areas of savanna in good condition (Woinarski et al. 2007). Second, there is evidence that elements of indigenous NRM have been continuing uninterrupted for thousands of years (Garnett and Sithole 2007), again a characteristic that is globally unique. Building up a distinctive brand around indigenous NRM in the tropical savannas could be very successful for securing financial support and at the same time for building up confidence that the program is effective.

Although, overall, respondents were willing to pay for indigenous NRM, a high percentage of respondents, particularly in the north, did not believe it is effective and/or thought that the government should pay for it. In terms of increasing donations, there may be particular merit in targeting people who are skeptical about the success of indigenous NRM with evidence of its achievements, as this is where the greatest gains could be made. One target group would be men living in northern Australia. It was moreover apparent that those most sympathetic to indigenous PES, women in southern cities with an interest in aboriginal culture, were either unaware of or had not absorbed the research demonstrating the extent to which involvement in NRM contributes to indigenous culture, health, and well-being. Instead these people were particularly attracted to the reduction in GHG emissions that can arise from indigenous NRM. Thus, this survey demonstrates opportunities for advocacy to increase support for indigenous NRM at both ends of the approval spectrum.

\section{Do negative attitudes in northern Australia impede paid indigenous natural resource management?}

It was surprising that respondents from the north valued the environmental services less than respondents from the south because other research investigating public perspectives on NRM either showed that variation in preferences is not explained by whether people are local or visiting (Hanley et al. 2010) or that the closer people live to an environmental asset the more they would be willing to pay to secure it, a phenomena referred to as 'sense of place' (Carlsson et al. 2003, Hanley et al. 2003). One explanation for why the majority of respondents in the north would not pay is that, as many stated themselves, they did not believe that indigenous people should be paid to provide environmental services. A particularly high 
Table 6. Examples of comments by respondents from the north on why they would be unwilling to pay for an indigenous Payments for Environmental Services program.

\begin{tabular}{ll}
\hline \hline Statement & Respondent's characteristics (Location', gender, age) \\
\hline "We pay so much and it's spent on alcohol! They can't manage their own houses, so won't be able & Darwin (NT), female, 42 \\
to manage bush." & \\
"Through personal dealing I do not believe creating additional jobs for Aboriginal people is cost & Palmerston (NT), female, 34 \\
efficient. ... There needs to be respect and commitment in all areas such as work ethic and general & \\
care for the environment we all share." & \\
"I will not donate for Aboriginals. They get enough from the government. They don't give a shit & Broome (QLD), male, 46 \\
$\begin{array}{l}\text { about this country as all the communities look like rubbish tips, and they are the most inhuman } \\
\text { when it comes to animals." }\end{array}$ & \\
"I feel that I have no obligation to pay for maintenance of 'private property'." & Darwin (NT), male, 66 \\
"Aboriginal people get far too much for nothing. White Australia is discriminated against.... maybe & Katherine (NT), male, 37 \\
evolution left them behind for good reason." & Broome (WA), male, 62 \\
"Aboriginal people generally have no work ethic whatever." & $\begin{array}{l}\text { Darwin (NT), female, 45 } \\
\text { "The most over subsidised race in the world already." }\end{array}$ \\
"They own the land, they should look after it, not the government or any other Australian." & South Hedland (WA), female, 32 \\
"If it's 'their land', they should look after it. If it's 'our land', then I am willing." & \\
"I live in Kununarra and see what giving blacks money does every day. It doesn't work and neither & Kununarra (WA), male, 50 \\
do they." & \\
"Taxes are wasted now. People should be self determining. Too much money given free now." & Broome (WA), male, 44 \\
\hline "NT: Northern Territory, QLD: Queensland, WA: Western Australia &
\end{tabular}

proportion of those unwilling to pay (about 60\%, compared with $10 \%$ who would pay) added a comment. Of these, $24 \%$ expressed some kind of negative attitude toward indigenous people as the reason (see Table 6 for examples) and 12\% described negative personal experiences with indigenous people. A further $16 \%$ of respondents did not believe in the program because they think that because it is indigenous private land, the traditional owners should look after it themselves, a sentiment in keeping with an attitude of selfreliance and disdain for either assistance or restrictions on personal freedoms in the Northern Territory (Instone 2009). These statements highlight the sensitivity of issues related to indigenous NRM. They also reflect the relatively high levels of racism in northern Australia, which itself contributes substantially to poor indigenous health (Larson et al. 2007, Paradies et al. 2008, Mansouri et al. 2009). However, as noted before, although the results may reflect a tendency in northern Australia, one cannot generalize to all northern Australian citizens. The people from the north who responded to the mailout survey probably wanted to voice strong opinions although those with milder views were possibly less likely to have returned the questionnaires.

Another explanation for not paying could be free-riding, a frequent problem when providing public goods and also observed with regard to indigenous NRM by Muller (2008). The Northern Territory population has the male bias and a high turnover of a resource-dependent society (Carson 2011). It follows that many temporary residents have little regard for an environment in which they will not be residing for long. It would appear that many respondents from the north were happy to use the environmental services of northern Australia for fishing and other activities while other respondents pay to maintain this environment. A good argument for translating peoples' willingness to pay for environmental services into real payments is that those who use the services can then pay for their maintenance, reducing free-riding on the unique environment of northern Australia.

\section{Outlook and further research}

What we can learn from the public perception of the north's natural resources can be important for future development of the north. Every now and then it is proposed that the north should be developed into a 'rice bowl' to achieve economic self-sufficiency and provide food to Asia (Australian Government 2009). The high values the Australian public places on the environment in the north (Zander et al. 2010) as one of the last remaining intact environments in Australia could be taken as an argument against developing the north for food production, in addition to the region's largely infertile soils, difficult climate, and high logistic costs.

The choice experiment results reveal a high level of interest in the ecological outcomes of indigenous NRM. An active area of research needs to be the distribution of social benefits among indigenous providers. Many NRM activities on indigenous-owned land are carried out by family groups and it can often be hard to identify who has delivered a certain environmental service, especially because many of the services are delivered for cultural reasons as part of complex social responsibilities. Notwithstanding calls to recognize individual rights of indigenous people as well as collective 
rights (Langton 2011), payments and other nonmonetary rewards may need to be distributed to individuals, among the families who are responsible for the land being managed, and to the whole community. Rewards may not even be payments but investments in commonly owned (public good) assets, indirectly benefiting the service providers (Clements et al. 2010, Farley and Costanza 2010). Overall more research is needed on appropriate vehicles for compensation and on how indigenous people can provide environmental services while complying with some level of conditionality and monitoring.

Although the needs of those who would pay, mostly nonindigenous people, eventually have to match the services that are provided, the capacity and willingness of indigenous people to provide the services is critical to any PES or other market-based incentive scheme's success. There is a risk that an indigenous concept may be transformed by nonindigenous people into a form of work that is no longer culturally appropriate, denying indigenous-controlled customary structures (Marika et al. 2009), and rendering them unattractive for indigenous people to pursue. Given that the primary motivations of indigenous people to be involved is cultural not monetary (Luckert et al. 2007), the strict assumptions of conventional PES schemes as conditional, well defined and voluntary (Wunder 2007) may need to be reconsidered. Hence, evaluating environmental services from a benefit-based approach, as I have done in this study, may be more appropriate than a rigid contractual link between the services to be provided and the manner in which this is to occur. Taking indigenous knowledge into account in the provision process is particularly important. Although I showed that respondents have preferences for some activities that they would like carried out for their money, indigenous people will often know best how to achieve the benefits from their services as well as the culturally appropriate ways of providing them. Nevertheless this research has demonstrated that Australians are willing to pay indigenous people substantially to prevent deterioration of the environment in northern Australia.

About $40 \%$ of respondents thought feral and dangerous animal control was the most important activity whereas only $11 \%$ thought that it was fire management, although this is the primary paid activity and the one that has the strongest links to indigenous NRM. However, respondents placed the highest value on the contribution by indigenous people to reducing GHG emissions. Although it was explained in the questionnaire preceding the choice experiment that GHG emissions are reduced through appropriate fire management (Appendix 2), respondents seem not to have made this connection when answering the questions. Again, this indicates a lack of understanding of indigenous land management as currently practiced.

\section{CONCLUSION}

A stated preference choice experiment was conducted using hypothetical scenarios that depict potential outcomes of indigenous NRM programs in northern Australia. Although the average value respondents would generally contribute to indigenous NRM was around A $\$ 300$, there was great variation. Those most likely to respond to calls for payments were women from southern Australia who are interested in indigenous culture. These respondents appreciated most the potential carbon services arising from indigenous NRM. Respondents least likely to contribute to an indigenous NRM program were people, particularly males, living in the north, suggesting a high degree of free-riding on the use of natural resources in the unique northern Australia landscape. From the lack of appreciation of the social benefits of indigenous involvement in NRM and the critical role of fire in both traditional and paid management, it is apparent that there is room for much better communication about existing research, which demonstrates that benefits do arise from payments for indigenous NRM. In fact, the current survey should be regarded as a baseline of public understanding of the issue on which an appropriately targeted publicity campaign could build if such schemes are to be self-funded based on the value perceived by Australian society.

[1] The West Arnhem Land Fire Abatement (WALFA) agreement was signed in August 2006 between Conoco Phillips, Indigenous Traditional Owners, and indigenous representative organizations and the Northern Territory Government. Conoco Phillips agreed to pay A $\$ 17$ million over 17 years from 2006 on for carbon abatements and to reduce greenhouse gas emissions (Whitehead et al. 2009).

Responses to this article can be read online at: http://www.ecologyandsociety.org/issues/responses. php/5267

\section{Acknowledgments:}

The research undertaken was funded by the ARC Discovery Grant DP0987528. I would like to thank Desleigh Dunnett and Stephen Garnet for discussion on these issues and Stephen Hamilton for proofreading the manuscript.

\section{LITERATURE CITED}

Adams, V. M., R. L. Pressey, and N. Stoeckl. 2012. Estimating land and conservation management costs: the first step in designing a stewardship program for the Northern Territory. Biological Conservation 148:44-53. http://dx.doi.org/10.1016/ j.biocon.2012.01.064 
Adamowicz, W.L., P.C. Boxall, M. Williams, and J. Louviere. 1998. Stated preference approaches for measuring passive use values: choice experiments and contingent valuation. American Journal of Agricultural Economics 80:64-75. http:// dx.doi.org/10.2307/3180269

Altman, J. 2007. Alleviating poverty in remote Indigenous Australia: the role of the hybrid economy. Centre for Aboriginal Economic Policy Research Discussion paper, Australian National University, Canberra, Australia.

Altman, J., G. J. Buchanan, and L. Larsen. 2007. The environmental significance of the Indigenous estate: natural resource management as economic development in remote Australia. Centre for Aboriginal Economic Policy Research Discussion Paper No. 286, Australian National University, Canberra, Australia.

Altman, J., and K. Jordan. 2009. The untimely abolition of the Community Development Employment Program. Topical Issue No. 5, Centre for Aboriginal Economic Policy Research, Australian National University, Canberra, Australia.

Australian Bureau of Statistics (ABS). 2006. Data \& analysis. ABS, Canberra, Australia. http://www.abs.gov.au/websitedbs/ censushome.nsf/home/data

Australian Government. 2009. Australia 2020 summit final report. Department of Prime Minister and Cabinet, Canberra, Australia.

Balmford, A., and T. Whitten. 2003. Who should pay for tropical conservation, and how could the costs be met? Oryx 37:238-250.

Bateman, I. J., R. T. Carson, B. Day, M. Hanemann, N. Hanley, T. Hett, M. Jones-Lee, G. Loomes, S. Mourato, E. Özdemiroglu, D. W. Pearce, R. Sugden, and J. Swanson. 2002. Economic valuation with stated preference techniques: a manual. Edward Elgar, Northampton, UK.

Burgess, C. P., F. H. Johnston, D. M. J. S. Bowman, and P. J. Whitehead. 2005. Healthy country: healthy people? Exploring the health benefits of indigenous natural resource management. Australian and New Zealand Journal of Public Health 29:117-122. http://dx.doi.org/10.1111/j.1467-842X.2005. tb00060.x

Campbell, D. 2011. Application of an integrated multidisciplinary economic welfare approach to improve wellbeing through aboriginal caring for country. Rangeland Journal 33:365-372. http://dx.doi.org/10.1071/RJ11025

Campbell, D., C. P. Burgess, S. T. Garnett, and J. Wakerman. 2011. Potential primary health care savings for chronic disease care associated with Australian aboriginal involvement in land management. Health Policy 99:83-89. http://dx.doi. org/10.1016/j.healthpol.2010.07.009
Carlsson, F., P. Frykblom, and C. Liljenstolpe. 2003. Valuing wetland attributes: an application of choice experiments. Ecological Economics 47:95-103. http://dx.doi.org/10.1016/ j.ecolecon.2002.09.003

Carson, D. 2011. Political economy, demography and development in Australia's Northern Territory. Canadian Geographer / Le Géographe canadien 55:226-242. http://dx. doi.org/10.1111/j.1541-0064.2010.00321.x

Clements, T., A. John, K. Nielsen, D. An, S. Tan, E. J. MilnerGulland. 2010. Payments for biodiversity conservation in the context of weak institutions: comparison of three programs from Cambodia. Ecological Economics 69:1283-1291. http:// dx.doi.org/10.1016/j.ecolecon.2009.11.010

Connor, J. D., J. Ward, C. Clifton, W. Proctor, and D. Hatton MacDonald. 2008. Designing, testing and implementing a trial dryland salinity credit trade scheme. Ecological Economics 67:574-588. http://dx.doi.org/10.1016/j.ecolecon.2008.01.020

Crouch, S., P. Robinson, and M. Pitts. 2011. A comparison of general practitioner response rates to electronic and postal surveys in the setting of the National STI Prevention Program. Australian and New Zealand Journal of Public Health 35:187-189. http://dx.doi.org/10.1111/j.1753-6405.2011.00687. $\underline{\mathrm{X}}$

Daily, G. C., S. Polasky, J. Goldstein, P. M. Kareiva, H. A. Mooney, L. Pejchar, T. H. Ricketts, J. Salzman, and R. Shallenberger. 2009. Ecosystem services in decision making: time to deliver. Frontiers in Ecology and the Environment 7:21-28. http://dx.doi.org/10.1890/080025

Dillman, D. A., J. D. Smyth, and L. M. Christian. 2009. Internet, mail and mixed-mode surveys - the tailored design method. Third Edition. Wiley, New Jersey, USA.

Engel, S., S. Pagiola, and S. Wunder. 2008. Designing payments for environmental services in theory and practice: an overview of the issues. Ecological Economics 65:663-674. http://dx.doi.org/10.1016/j.ecolecon.2008.03.011

Farley, J., and R. Costanza. 2010. Payments for ecosystem services: from local to global. Ecological Economics 69:2060-2068. http://dx.doi.org/10.1016/j.ecolecon.2010.06.010

Ferraro, P. J., and R. D. Simpson. 2002. The cost-effectiveness of conservation payments. Land Economics 78:339-353. http://dx.doi.org/10.2307/3146894

Garnett, S. T., and B. Sithole. 2007. Sustainable northern landscapes and the nexus with indigenous health: healthy country healthy people. Land and Water Australia, Canberra, Australia.

Garnett, S. T., B. Sithole, P. J. Whitehead, C. P. Burgess, F. H. Johnston, and T. Lea. 2009. Healthy country, healthy people: policy implications of links between indigenous 
human health and environmental condition in tropical Australia. Australian Journal of Public Administration 68 (1):53-66. http://dx.doi.org/10.1111/j.1467-8500.2008.00609. $\mathrm{X}$

Garnett, S. T., J. Woinarski, R. Gerritsen, and G. Duff. 2008. Future options for north Australia. Charles Darwin University Press, Darwin, Australia.

Green, D. 2008. Climate impacts on the health of remote northern Australian indigenous communities. Garnaut Climate Change Review, Department of Climate Change and Energy Efficiency, Canberra, Australia.

Hanemann, W. M. 1984. Welfare evaluations in contingent valuation experiments with discrete responses. American Journal of Agricultural Economics 66:332-341. http://dx.doi. org $/ 10.2307 / 1240800$

Hanley, N., M. Czajkowski, R. Hanley-Nickolls, and S. Redpath. 2010. Economic values of species management options in human-wildlife conflicts: hen harriers in Scotland. Ecological Economics 70:107-113. http://dx.doi.org/10.1016/ j.ecolecon.2010.08.009

Hanley, N., F. Schläpfer, and J. Spurgeon. 2003. Aggregating the benefits of environmental improvements: distance-decay functions for use and non-use values. Journal of Environmental Management 68:297-304. http://dx.doi. org/10.1016/S0301-4797(03)00084-7

Hanley, N., R. E. Wright, and V. Adamowicz. 1998. Using choice experiments to value the environmental. Environmental and Resource Economics 11:413-428. http://dx.doi. org/10.1023/A:1008287310583

Hanley, N., R. E. Wright, and B. Alvarez-Farizo. 2006. Estimating the economic value of improvements in river ecology using choice experiments: an application to the water framework directive. Journal of Environmental Management 78:183-193. http://dx.doi.org/10.1016/j.jenvman.2005.05.001

Hensher, D. A., and W. H. Greene. 2003. The mixed logit model: the state of practice. Transportation 30:133-176. http:// dx.doi.org/10.1023/A:1022558715350

Hensher, D. A., J. M. Rose, and W. H. Greene. 2005. NLOGIT for applied choice analysis: a primer. Cambridge University Press, Cambridge, UK. http://dx.doi.org/10.1017/ CBO9780511610356.008

Hunter, B. 2006. Revisiting the poverty war: income status and financial stress among indigenous Australians. Pages 91-102 in B. Hunter, editor. Assessing the evidence on indigenous socioeconomic outcomes: a focus on the 2002 NATSISS. Australian National University E Press, Canberra, Australia.
Institute of Transport and Logistics Studies. 2007. Ngene - a software capability to design and generate choice experiments. The University of Sydney, Sydney, NSW, Australia.

Instone, L. 2009. Northern belongings: frontiers, fences, and identities in Australia's urban north. Environment and Planning A 41(4):827-841. http://dx.doi.org/10.1068/a41168

Johnston, F. H,, S. P. Jacups, A. J. Vickery, and D. M. J. S. Bowman. 2007. Ecohealth and aboriginal testimony of the nexus between human health and place. EcoHealth 4:489-499. http://dx.doi.org/10.1007/s10393-007-0142-0

Krinsky, I., and A. L. Robb. 1986. On approximating the statistical properties of elasticities. Review of Economics and Statistics 68:715-719. http://dx.doi.org/10.2307/1924536

Langton, M. 2011. Anthropology, politics and the changing world of aboriginal Australians. Anthropological Forum: a Journal of Social Anthropology and Comparative Sociology 21:1-22. http://dx.doi.org/10.1080/00664677.2011.549447

Larson, A., M. Gillies, P. J. Howard, and J. Coffin. 2007. It's enough to make you sick: the impact of racism on the health of aboriginal Australians. Australian and New Zealand Journal of Public Health 31(4):322-329. http://dx.doi. org/10.1111/j.1753-6405.2007.00079.x

Luckert, M., B. M. Campbell, J. T. Gorman, and S. T. Garnett. 2007.Investing in indigenous natural resource management. Charles Darwin University Press, Darwin, Australia.

Mansouri, F., L. Jenkins, L. Morgan, and M. Taouk. 2009. The impact of racism upon the health and wellbeing of young Australians. Settlement Council of Australia, Surry Hills, NSW, Australia.

Marika, R, Y. Yunupingu, R. Marika-Mununggiritj, and S. Muller. 2009. Leaching the poison - the importance of process and partnership in working with Yolngu. Journal of Rural Studies 25:404-413. http://dx.doi.org/10.1016/j.jrurstud.2009.05.007

McDermott, R., K. O'Dea, K. Rowley, S. Knight, and P. Burgess. 1998. Beneficial impact of the Homelands Movement on health outcomes in central Australian Aborigines. Australian and New Zealand Journal of Public Health 22:653-658. http://dx.doi.org/10.1111/j.1467-842X.1998. tb01464.x

McFadden, D. 1974. Conditional logit analysis of qualitative choice behaviour. Pages 105-142 in P. Zarembka, editor. Frontiers in Econometrics. Academic Press, New York, USA.

Meyerhoff, J., and U. Liebe. 2009. Status quo effect in choice experiments: empirical evidence on attitudes and choice task complexity. Land Economics 85:515-528. 
Millennium Ecosystem Assessment (MEA). 2003. Ecosystems and human well-being: a framework for assessment. World Resources Institute and Island Press, Washington, D.C., USA.

Muller, S. 2008. Indigenous payment for environmental service (PES) opportunities in the Northern Territory: negotiating with customs. Australian Geographer 39:149-170. http://dx.doi.org/10.1080/00049180802056831

Muradian, R., E. Corbera, U. Pascual, N. Kosoy, and P. H. May. 2010. Reconciling theory and practice: an alternative conceptual framework for understanding payments for environmental services. Ecological Economics 69:1202-1208. http://dx.doi.org/10.1016/j.ecolecon.2009.11.006

Paradies, Y., R. Harris, and I. Anderson. 2008. The impact of racism on indigenous health in Australia and Aotearoa: towards a research agenda. Discussion Paper No. 4, Cooperative Research Centre for Aboriginal Health, Darwin, Australia.

Pearson, D. M., and J. T. Gorman. 2010. Managing the landscapes of the Australian Northern Territory for sustainability: visions, issues and strategies for successful planning. Futures 42:711-722. http://dx.doi.org/10.1016/j. futures.2010.04.008

Rapidel, B., F. DeClerck, J.-F. Le Coq, and J. Beer. 2011. Ecosystems services from agriculture and agroforestry: measurement and payment. Earthscan, London, UK.

Rose, J. M., M. C. J. Bliemer, D. A. Hensher, and A. T. Collins. 2008. Designing efficient stated choice experiments in the presence of reference alternatives. Transportation Research Part B: Methodological 42:395-406. http://dx.doi.org/10.1016/ j.trb.2007.09.002

Scrimgeour, D. 2007. Town or country: which is best for Australia's indigenous peoples. Medical Journal of Australia 186:532-533.

Smith, R. J., D. Veréssimo, and D. C. MacMillan. 2010. Marketing and conservation: how to lose friends and influence people. Pages 216-232 in N. Leader-Williams, W. M. Adams, and R. J. Smith, editors. Trade-offs in conservation: deciding what to save. Wiley-Blackwell, Chichester, UK. http://dx.doi. org/10.1002/9781444324907.ch12

The Economics of Ecosystems and Biodiversity (TEEB). 2010. The economics of ecosystems and biodiversity: mainstreaming the economics of nature: a synthesis of the approach, conclusions and recommendations of TEEB. TEEB, Geneva, Switzerland.

Train, K. 1998. Recreation demand models with taste differences over people. Land Economics 74:230-239. http:// dx.doi.org/10.2307/3147053
Train, K. 2003. Discrete choice methods with simulation. Cambridge University Press, Cambridge, UK. http://dx.doi. org/10.1017/CBO9780511753930

von Haefen, R. H., D. Matthew Massey, and W. L. Adamowicz. 2005. Serial nonparticipation in repeated discrete choice models. American Journal of Agricultural Economics 81:1061-1076.http://dx.doi.org/10.1111/j.1467-8276.2005.00794. $\underline{x}$

Whitehead, P. J., P. Purdon, P. M. Cooke, J. Russell-Smith, and S. Sutton. 2009. The West Arnhem Land Fire Abatement (WALFA) project: the institutional environment and its implications. Pages 287-312 in J. Russell-Smith, P. J. Whitehead, and P. M. Cooke, editors. Culture, ecology and economy of fire management in north Australian savannas: rekindling the wurrk tradition. CSIRO Publishing, Collingwood, Australia.

Woinarski, J., B. Mackey, H. Nix, and B. Traill. 2007. The nature of northern Australia: its natural values, ecological processes and future prospects. Australian National University E-Press, Canberra, Australia. http://epress.anu. edu. au? $\mathrm{p}=34501$

Wunder, S. 2007. The efficiency of payments for environmental services in tropical conservation. Conservation Biology 21:48-58. http://dx.doi.org/10.1111/j.1523-1739.2006.00559. $\underline{\mathrm{x}}$

Zabel, A., and S. Engel. 2010. Performance payments: a new strategy to conserve large carnivores in the tropics? Ecological Economics 70:405-412.

Zander, K. K., S. T. Garnett, and A. Straton. 2010. Trade-offs between development, culture and conservation - willingness to pay for tropical river management among urban Australians. Journal of Environmental Management 91(12):2519-2528. http://dx.doi.org/10.1016/j.jenvman.2010.07.012 
Appendix 1. Example of a choice set included in the questionnaire.

Health of native animal and plant communities

$$
\text { Improving }
$$

Attractiveness for recreational use

Benefits to Aboriginal people

Less dependency
Good
Stable

Ok Better transfer of Indigenous knowledge

Increasing
Stable

Ok

No additional benefits
Greenhouse gas abatement

Your annual payment (in AUS\$)
Stable $\$ 25$
$\$ 50$
Declining 
Appendix 2. Part of the questionnaire preceding the choice experiment and describing activities and their outcomes of indigenous natural resources management.

\begin{abstract}
Many aboriginal people in northern Australia have the knowledge and desire to look after their country. While government supports some Aboriginal ranger groups to provide care for the environment much more could be done and more people employed if more money was available. One solution could be to set up a conservation management fund. Public donations would be placed in a trust from which Aboriginal people could be paid to manage activities such as:
\end{abstract}

A) Reducing fire frequency and intensity by proper fire management.

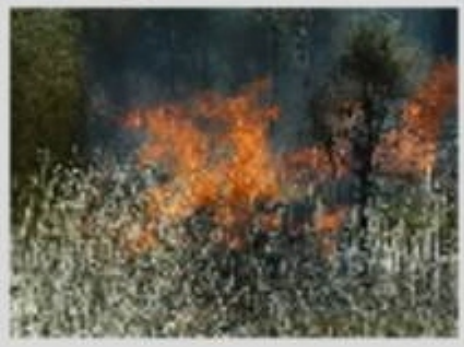

- This leads to lower emissions of greenhouse gases which are one of the reasons for global warming.

- It protects fire-sensitive native animals and plants.

- It protects infrastructure from burning down

C) Controlling feral animals like camels and dangerous animals like crocodiles.

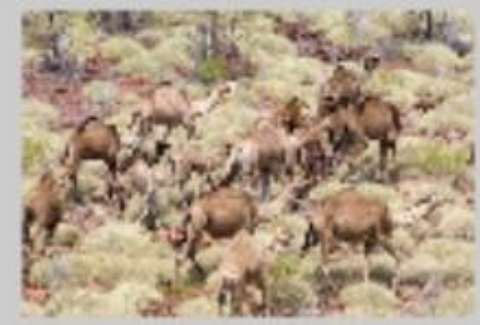

- This protects native animals because feral animals prey on native species, compete with them for food and destroy their habitat.

- It has recreational value because managing crocodile traps makes it safer for people to be near water.
B) Coastal surveillance and management, including the control of ghost nets.

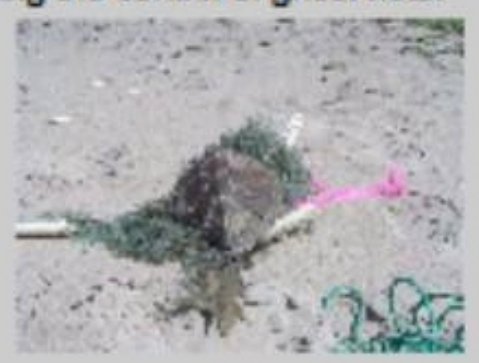

- It protects marine animals.

- It stops exotic pests from coming into Australia from debris washed up onto beaches.

- It decreases the level of pollution on beaches and makes them more attractive for recreation.

D) Controlling noxious weeds.

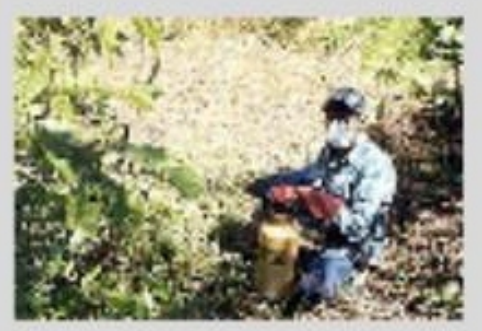

- This prolects native plants, wetlands and woodlands from being taken over by weeds.

- Outdoor activities such as bushwalking and fishing can also become more attractive when weeds are eradicated.

- It reduces fire hazards. 